\title{
From AgwA to Oversize: from design practice to a pedagogic and research project
}

\author{
B. Burquel \\ Civil Engineer architect, assist. ULB faculty of Architecture
}

H. Fallon

Civil Engineer architect, PhD, assist. Prof. KULeuven faculty of Architecture

B. Vandenbulcke

Civil Engineer architect, PhD, assist. Prof. Uliège faculty of Architecture

\begin{abstract}
This paper explores several projects of the author's architecture practice. These projects address the transformation and reuse of existing large scales structures. Through time, the use of the buildings is questioned. The nature of the activity changes, the scale differs, the needs evolve, the regulations are modified. It concludes with the details of the academic project "Oversize" as a pedagogic and research project.
\end{abstract}

\section{INTRODUCTION}

Buildings that are too large, spaces that are too high, ceilings that are too low. Constructions that seem unfit to host today's paraphernalia of technical equipment. Empty factories, empty office blocks. Unwanted housing complexes. Poorly insulated edifications. Abandoned train stations, empty monasteries and vacant churches. The list is endless.

As the population stagnates more or less in western Europe, as the shift towards a service economy goes on, as buildings become obsolete due to evolving regulations and norms, and as ecology asks to consider our environmental footprint globally, one wonders why the demolition and reconstruction frenzy seems to be unstoppable.

AgwA, the authors' architecture practice based in Brussels, has been confronted with these topics through the last years, and not only through the politically correct but uninspired refurbishment of former industrial plots into ill-defined cultural centers. These experiences start to define a coherent practice, an operational approach that is now being engaged as a research and pedagogic project.

Since 2016, we are working on the refurbishment project of the Exhibition Palace of the City of Charleroi (CHAPEX), a huge complex of exhibition halls nearing $60.000 \mathrm{sqm}$ in the heart of this small city housing about 200.000 inhabitants. It would be a dense party, but the entire city population could fit in these halls. Clearly, the complex is inherited from the glorious industrial past of the city. In 2017, it has become way too large in regard to the current uses. Venue managers told us that a mere $25.000 \mathrm{sqm}$ would be more than enough for a city of this scale. Of course, the budget is ridiculously low: about 350 euros/sqm excluding taxes, instead of the usual 1250 used for rational, no-nonsense refurbishments.

The acute consciousness of this situation and the exploration of its potentialities coincided with other similar projects, like the competition for a new archive and contemporary arts museum in the former Citroën workshops in Brussels, like the refurbishment of Metal, an ancient tyre workshop in Brussels into a sports hall and evening school, like the restructuration of the former ECAM site into sports facilities, a kindergarten, office spaces and a public park, and like, on a smaller scale, the refurbishment of a storage building Verbiest into a house and workshop. 
Recently, we had the opportunity to work with Muck Petzet on two projects, and discovered his work "Reduce, Reuse, Recycle - Architecture as a resource", where he advocates for a positive consideration of the existing architecture, regardless of its supposed aesthetics and qualities.

Simultaneously, a new architecture guide on the city of Charleroi was published in 2017. Its share of beautifully intriguing yet empty buildings is astonishing. Typically, the type of buildings that would be demolished and replaced by shiny high-tech nonsense and commercial, flavorless developments.

As the three partners of the office are engaged in research and education, we decided to launch an academic project named "Oversize". In Muck Petzet's words, it explores the idea that buildings are a resource we should take advantage of. Specifically, it concentrates on the potential of lowdensity use: architectural emptiness as a resource. Having in mind that this only makes sense when combined with extreme precaution regarding the (financial) means.

What happens if we consider that every piece of architecture is doomed to become obsolete? What happens if we consider that this obsolescence is an opportunity rather than a problem? Could we not consider these structures as gifts that we should consider using, rather than cumbersome constructions we should get rid of? Empty buildings indicate a lack of use. What if we consider that this emptiness is also an opportunity? What if we turn away from the real estate dream of the $100 \%$ sold surfaces?

"Oversize" was selected as an Academic Design Office (ADO) at the faculty of architecture of the KU Leuven. ADO's are transversal academic projects combining design practice, design education and research. "Oversize" is developed together with ULB, ULiège and UCL, partnering with $\mathrm{A}+$, the main Belgian architecture review.

This paper unveils and observes several design processes at AgwA in the framework of projects related to Oversize and relates them to other practices. It concludes with the details of the Oversize Academic Design Office, both as a pedagogic and research project.

\section{METAL - FLEXIBLE STRUCTURAL PRINCIPLES}

The Metal project dates back from 2006-2009 and has already been widely published and exhibited. Particularly, it formed a key element of the $\mathrm{PhD}$ of one of the authors (Metarbitrariness - AgwA, an architecture of practice). Metal is an ancient tyre workshop, a large concrete skeleton covering spaces intended to become a sports hall and an evening school, together with three apartments.

The research shows how this structure becomes the opportunity for the design of a variety of structural elements, forming a coherent collection in its diversity. The simplicity of the principle of these beams spanning the entire space allows to adapt easily to each situation. Its evidence also ensures that fragile detailing becomes secondary. Architectural robustness through the primacy of rough structures.

The oversize element is not fundamentally present in this project, in the sense that in the end, the functional program fills the available space. But retrospectively, it should be noted that the architectural approach focusing on the use and extension of existing structures is a strong tool towards spatial polyvalence. When the tyre workshop was first intended for a boxing club, and then as a ping-pong space, it became a gymnastic hall. Different users, different expectations, but they all could be housed in the same space. Probably, the generous height of the space, the zenithal light, the roughness of a space that does not seem to be intended for a specific use, ensures that future users adapt willingly to the small constraints of a somehow "unfit" space and discover new, unexpected possibilities in the provided structures. The roughness, the simplicity of the materials, are all invitations to use and transform them generously. 


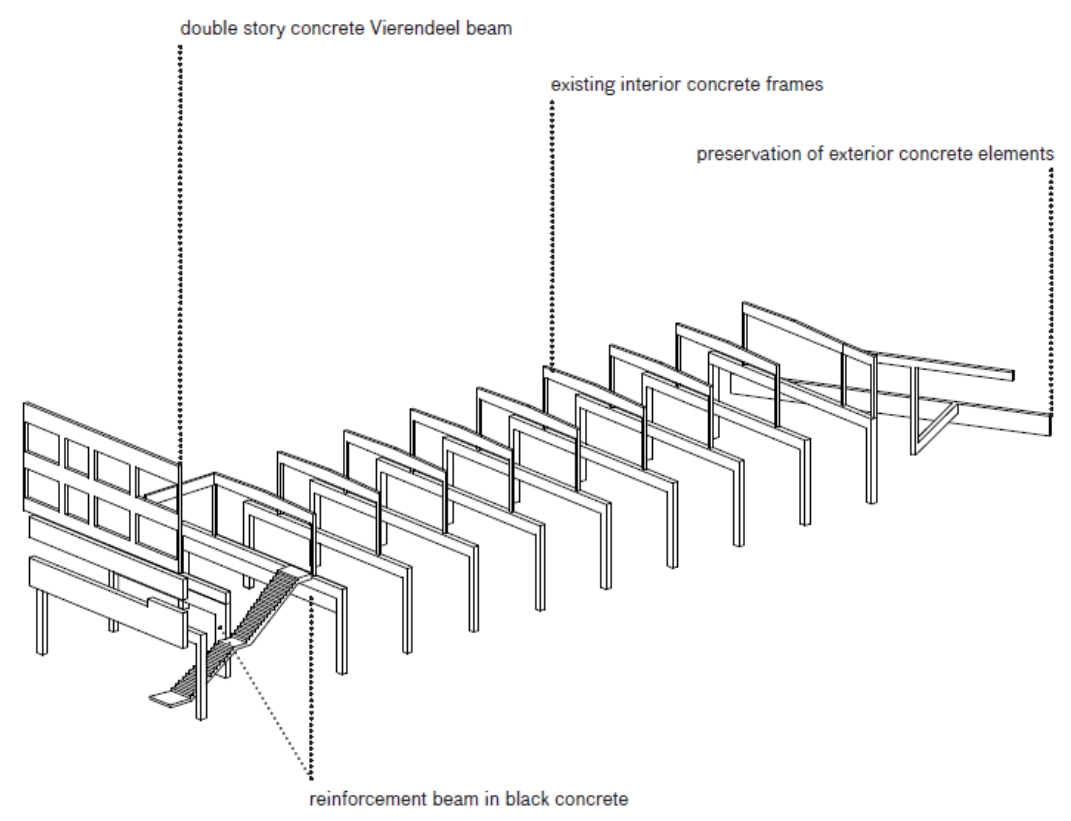

Figure 1. Metal (AgwA - Ferrière), structural scheme (AgwA)

\section{ECAM - STRUCTURAL IDENTITIES, DEFRAMED USE}

New buildings, demolitions, refurbished spaces and a public park form the complex assignment for the ECAM site in Brussels. The existing buildings date from the very early 1900s until the late 1980s. There will be a kindergarten, sports facilities, offices and educational spaces, an open workshop, a cafeteria, an information point. All in all, there are about 10 buildings. Will it become a culinary festival? Or a uniform taste with a thick common sauce applied to all dishes? And are these uses fixed on the long term? How can we anticipate change? And how can we address the budgetary limitations?

\subsection{Structural identities}

First, as each of the three main existing buildings is very different from the others, it seems artificial to attempt to force them into a coherent whole. Each of the additions will bear its own identity too. Nevertheless, they share a kind of rigorous systematism, that goes through the entire collection. Rhythmic facades, repetitive structures, a restrained expression. The new buildings expand this attitude. They are defined by simple structural typologies, which define their expression and identity. These "naked structures" remind us of Metal in a way: even if they are fit to the specific uses of the program, they could also absorb almost any programmatic changes. There is a sense of slightly augmented dimensions, that allow this appropriation of the space, just as it happens with the existing buildings.

These structures are self-centered: each element forms a complete shape (gestalt) on its own. This way, further evolution is facilitated. Parts of the project could be amended, removed, provided with additions. The project does not aim a rigidly perfected condition. Rather, it is a current state of affairs, which attains a certain stability, but allows change and evolution. Simultaneously, these structures share their essential openness and rigor in proposing constructive structures that immediately define their architectural identity. Just as in Metal, architectural malleability is ensured, but here, it happens rather at the scale of the site, of a collection of buildings.

We could refer here to the project for a sports and sailing complex in Péronnes-lez-Antoing, in which a constructive grammar was developed in order to provide coherence to a set of buildings. Here, maybe, to extend the linguistic metaphor, it is rather a family of languages sharing common roots. A higher degree of diversity. 


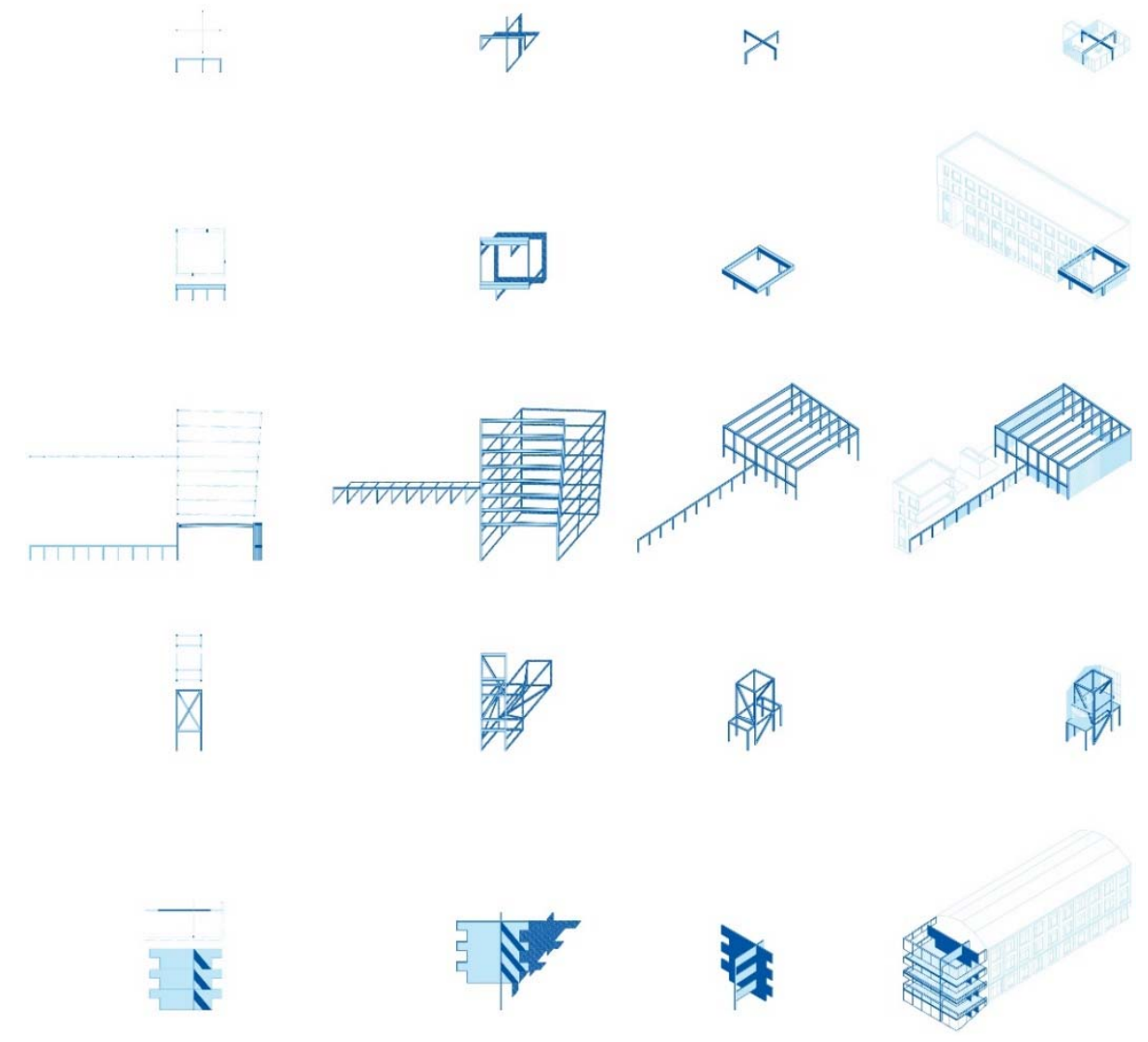

Figure 2. ECAM, Atlas of new structures (AgwA)

\subsection{Deframed uses}

Second, many uses are loosely defined, by the client on one side, and also by us on the other. This is made possible by oversizing spaces, horizontally, vertically, or both, in existing structures or in new constructions.

In one of the buildings, there are spaces for offices and associations, like a housework program, but some spaces are also to be delivered without finishing. In this building, the main interventions are concentrated on the vertical shafts making these uses possible.

Departing from a budgetary consideration, we proposed at some point to build an outdoor covered sports hall rather than a completely equipped and insulated one. By doing this, the structure appears completely naked. And uses change. The relationship with the public space is transformed.

A former school building will host a large kindergarten. This typological change produces fertile confrontations: too large, too high, too long spaces are included in the standardized program of the kindergarten. This offer unexpected spatialities almost impossible to design within a new kindergarten. Unadapted spaces able to generate new uses and appropriations: a large corridor becomes the extension of the different classrooms, a long space where to ride bicycles, where children of different ages, parents and nurses meet, an antechamber for the common garden.

A new access to the park is created between two houses. A structure is required to ensure the stability of the neighbors. We proposed to roof this structure. The space becomes the "park workshop", a space with no predefined use, unheated, levitating between park and street, a unique room with a very high ceiling. A space for an artist, for an event, for experimentation, for workshops with kids: a prospective oversize. It is not really about removing the frames. It is rather about loosening them. 


\section{CHAPEX - EXTENSIVITY, INTENSIVITY: ON THE (DE-)CONCENTRATION OF USES}

This huge building consists of two times three superposed halls around a monumental circulation space. As the available surface exceeds widely the needs, the brief defines that the lower level should be used to house a multilevel parking, and that the central space should be demolished and replaced by a "contemporary volume".

As the budget does not allow to build additional structures, we proposed to maintain the central spaces and remove their façade: these spaces become a layered outdoor, covered place distributing the halls.

During the process, the administration in charge of the energy performances mentions that inside walls and slabs that now become a contact between heated spaces and the exterior should be insulated. The project reaches therefore an impasse, as the surfaces to be insulated are enormous. After an attempt to reduce drastically the heated spaces by defining boxes inside the halls, which could not solve the financial issue and caused functional problems, we finally proposed to concentrate hall the exhibition activities on one side of the central halls. Three superposed halls with three clearly defined identities: one naturally lighted hall below the industrial sheds, one fragmented and already equipped hall for the smaller events, and one new, large black box. Facing these three superposed halls, the three other halls are left "as is" and house parking. In this way, each hall has its own privileged parking. Also, the heated spaces are really concentrated: the investment is optimal (we even manage to renew the old leaking sheds). The parking halls remain unchanged, with ceiling heights ranging between 8 and 10 meters. Exhibitions and events can naturally also take place here. Small entrance pavilions and additional structures, such as staircases, escalators and elevators, ensure the renewed functionality of the whole.

On one side, the intensively used halls. On the other side, the extensive parking with limited capacity and an extraordinary generosity. In the middle a vast outdoor "park" distributed over three levels, connecting the halls and the parkings, the city center, the ring road and the landscape of the periphery.

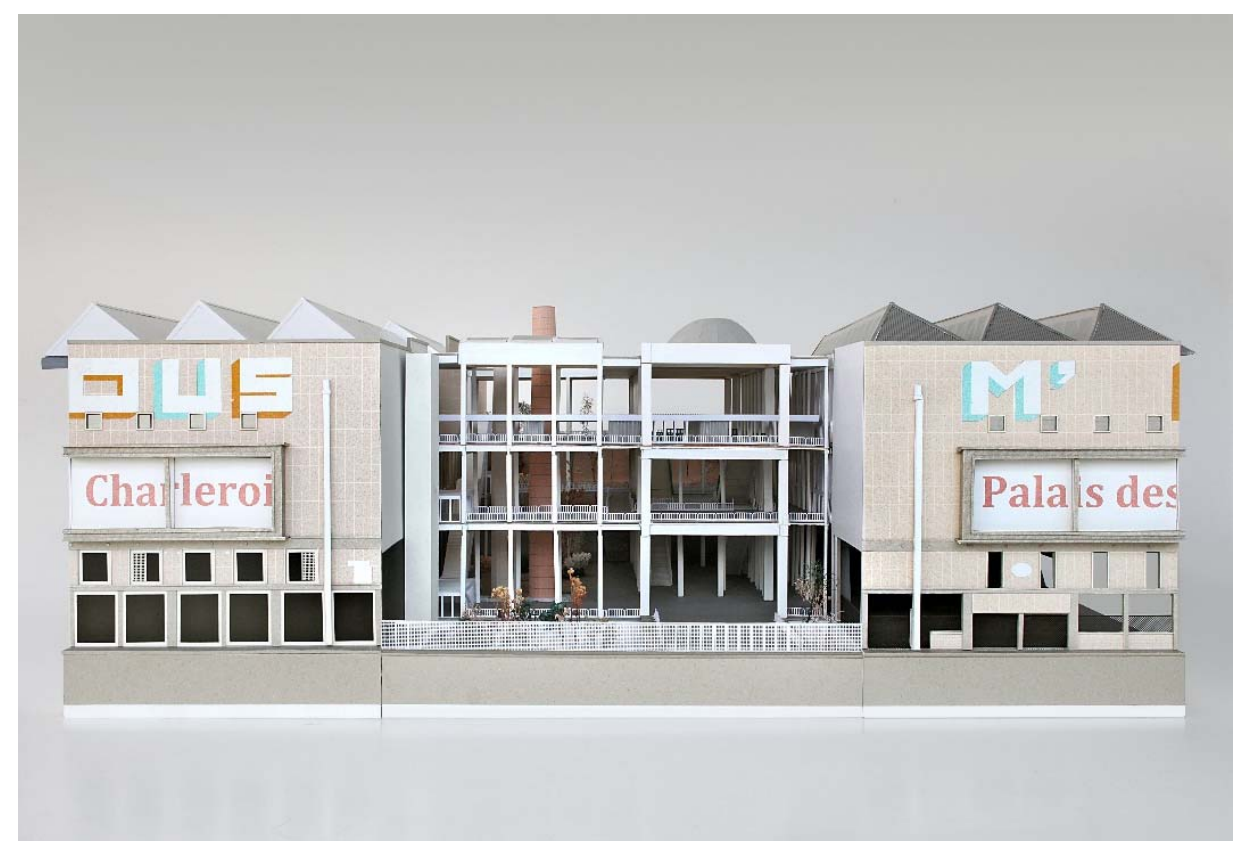

Figure 3. CHAPEX (advvt-AgwA), model picture (P. Dujardin) 
We are still facing a dilemma in the project. As the old concrete structures of the late fifties now become partly exterior structures, the control office and the structure consultants propose to apply an anti-carbonatation coating. Beyond the ugliness of this $5 \mathrm{~mm}$ thick synthetic layer, this poses a financial issue: the cost of about 1.000 .000 euro could be otherwise invested in functional necessities or maybe in the renovation of leaking roofs. There is a difficulty to anticipate the evolution of the carbonatation. We know that the exposed structure will be ruined over time if no treatment is applied. But when? Is it worth protecting the structure with this heavy solution, when we cannot anticipate future uses? Is a programmed ruin a possible strategy? Is postponing this investment an option? Or a maintenance program in order to detect at best the moment in which the coatings become a necessity?

\section{VERBIEST - MAINTAINING, CUTTING, ADDING, CONNECTING, PASTING, REPAIRING, REINFORCING, REMOVING: ON LOCAL ACTIONS AND THE EXCESS OF SPACE}

This project is about the refurbishment of a concrete structure that once housed a commercial storage into a house with a workshop. It is distributed over three levels and situated inside a triangular city block. Built in several phases, located in a complicated context, with no exterior space, the structure then also appears to admit only very limited loads. But it is large: about a thousand square meters.

In regard of the size of the plot, the interventions need to be precisely circumscribed in order to keep the budget under control. These interventions are not linked with each other. It is the existing building that confers the coherence to the whole. On the ground floor and on the first floor, three exterior spaces are created. The existing concrete skeleton is maintained (it will be an experiment on carbonatation!), as well as the existing walls delimiting the spaces. On the ground floor, a unique long wall organizes the functionality of the workshop. In the house, a vertical void is created, housing a robust wooden staircase. The floors are doubled with a massive wooden slab, made of juxtaposed small beams. This solves the limited loads. The roof is partially rebuilt following the original model. Half of it is replaced by an agricultural greenhouse. Hemp blocks insulate the building from the inside. The entire process consists in precisely defining these interventions and additions. Some disappeared, like a modification of the volume of the roof. Some were modified, like the geometry of a triangular patio that at once adapted to existing geometries. Or like the longitudinal wall that in the first sketches was curved. It is about the formal reduction of initial intuitions, and about the sharpening of the nature of each action.

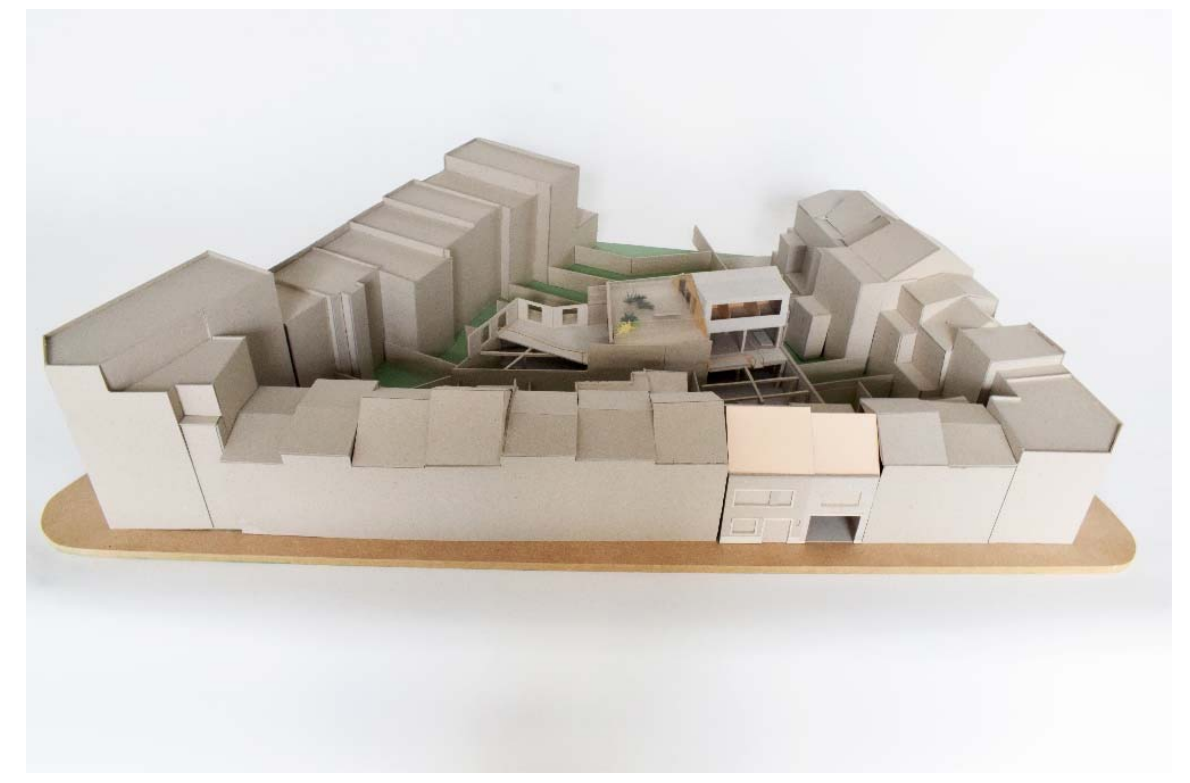

Figure 4. Verbiest (AgwA), model picture (D. Mathy) 
Observing these projects in our contemporary context, we discovered several advantages of reusing old structures beyond their formal appeal. First in term of space: oversized structures offer spatial qualities and generosity which are almost unthinkable to design within current Belgian energy policies or economical context. Second in term of energy: current energy policies focus on performances and rarely include the grey energy linked with construction and demolition. Maintaining structures drastically decreases the global footprint of a project and makes it energetically equivalent to a similar passive project including demolition. Third in term of sustainability in a broad sense: reusing existing structures often imposes to make a more extensive use of workforce while limiting the use of new industrial materials. In this sense, such approach plays a new social role in our society of industrialization.

Finally, such approach enables to maintain architectural heritage in life and to let it evolve without annihilating it. In this sense, oversize stresses the political content of an architectural approach: the societal meaning of adapting and reducing structures, of maintaining oversized buildings, of valuating unadaptation. This work opens for us a new field to be investigate also in the framework of our academic functions in term of teaching and researching.

\section{OVERSIZE - TOWARDS AN ACADEMIC PROJECT}

The conceptual flexibility of structural typologies, the deframing of uses, the diversity of architectural (structural) identities, the reorganization of intensive and extensive uses, the irreducibility of local actions on existing structures empowering uses. As objects, these buildings all seem to grant new possibilities through some kind of generosity of the spaces and of the structures. Each project is the opportunity of specific accents and strategies.

There is a conceptual and aesthetic richness at work in these situations. There is also a richness in the functional opportunities. There is a beauty in the gap between the nature of the spaces and the uses they afford. There is also, of course, an ecological pertinence in addressing these situations in a constructive way, instead of systematic demolition.

OVERSIZE was proposed as an ADO (Academic Design Office) at the KU Leuven, in collaboration with ULB, UCL and ULiège and in collaboration with $\mathrm{A}^{+}$, the Belgian Architecture Review. This project runs over three years.

In 2018-2019, OVERSIZE focuses on Charleroi with several pedagogic studios, which are described below. The results of the studios will be presented in an exhibition and collected in a publication, together with architectural projects defining a current community of practice. The Oversize ADO is an opportunity for exchange between universities, which is formalized during the year through transversal workshops.

OVERSIZE CHARLEROI (KU Leuven) is a master dissertation studio for ten students. Each student elaborates a design proposal on two buildings located in Charleroi, designed by the same architect. The buildings are selected from the recent architecture guide of the city of Charleroi. This is an opportunity to explore the oeuvre of these (often quite forgotten) architects and to develop a design proposal with oversize in mind.

CONJECTURAL ARCHITECTURE (KU Leuven) - Charleroi is an elective studio in the masters in which the students develop the oeuvre of a fictional architect living and working in Charleroi and who is related to one of the architects from the Oversize Charleroi studio. This work sheds a lateral light on the city, its history and the architects. It fertilizes the reflection of the other studios.

ATELIER XX (ULiège) is a studio in the masters addressing existing buildings from the XXth century. The students work on two large buildings in the city of Charleroi. The first one is ancient military barracks from the 1930's, from an unknown architect. A quite generic building with plain, 
repetitive structures. The second is an expressive tectonic multiple-purpose building from the 1970's, formerly housing a hotel, offices, a restaurant, etc. The studio is completed by a "monography course" in which a complete survey of the buildings is realized. The buildings are selected from the recent architecture guide of the city of Charleroi.

ATELIER 5 (ULB) is a introductory studio for the first bachelor. The studio explores several places in the city of Charleroi, in which students develop a simple design proposal.

MICROMEGAS LAB (ULB) is an urbanism and architecture studio, in which students realize a large hand drawn map and videos with the city as subject (mega), and then make very small, acupuncture design proposals (micro).

CONSTRUCTION 2 (UCL) is a studio focusing on construction that will be developed in the second half of the year. The subjects will be similar items as the Oversize Charleroi and the Atelier XX studios.

In this constellation, all studios address the city of Charleroi through architecture design proposals. Three studios address the Oversize theme frontally. The other studios contextualize them: conjectural architectures is conceptual, micromegas lab is about the large scale, etc. The ADO is not seen as a constraining frame, but rather as a context facilitating collaborations.

The first transversal workshop was held in november, with lectures by Inge Vinck sharing her experience on projects related to the topic (Caritas, Chapex,...) and by Pauline Cabrit (representing the city architect of Charleroi) sharing their work and strategies for the development and the quality of the city. The workshop was housed at the Universite du Travail and the contemporary arts museum BPS22. These local collaborations are also fruitful in allowing a greater sensibility to the local reality. The first results of the studios were displayed and the day ended with a short, playful assignment on the Palais des Expositions addressing the sense of scale.

The publication that will follow the conclusion of the studios will be the opportunity for a cross-disciplinary, retrospective reflection on the delivered works and on architecture projects (professional, research and student work).

For the two next years, we will develop this ADO further, focusing on other sites or cities, in which the topic has some particular relevance. It may allow different collaborations and encounters.

\section{FROM PRACTICE TO ACADEMICS, BACK TO PRACTICE, AND TOWARDS THE FIELD}

From AgwA to Oversize is an example of how themes appear in a running practice, and how these themes become active as an academic project involving research, pedagogy, dissemination and interaction.

Of course, as the practice is running, new projects are started, and former projects evolve. We wonder how the academic projects will have a feedback effect on the practice, and how the evolving practice will influence further the definition of the design strategies at work in the studios.

This relationship between the practice and the academic ADO is not a closed relationship. The first transversal workshops showed the mutual enrichment with actors from the field, like practicing architects and administrative actors. The publication and the exhibition at the end of this first year of experiment will hopefully confirm this. 